\title{
Why do we need environmental monitoring for Everglades restoration? ${ }^{1}$
}

\author{
Frank J. Mazzotti, Nicola Hughes, and Rebecca G. Harvey ${ }^{2}$
}

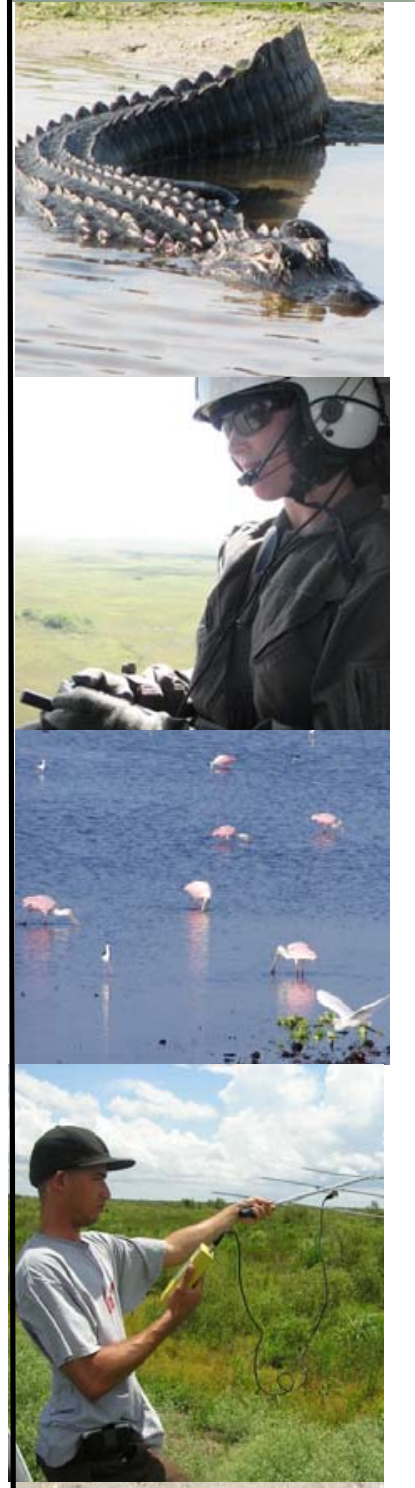

\section{What is monitoring?}

We use monitoring in everyday life to keep track of weather, stocks, gas prices, traffic patterns, and housing costs. We make decisions, such as whether to go out or not or if we should buy or rent, based on this information. We also monitor our health by evaluating how we feel and with regular health checks. Monitoring keeps us informed, helps us to maintain our health, and alerts us to future problems that may arise.

Monitoring ecosystems is similar to monitoring human health. There are both short-term and longterm indicators of ecosystem health. In general, however, ecosystems require long-term monitoring because they are complex and sensitive, and because they change slowly. Ecosystem monitoring means measuring physical, chemical, and/or biological variables over time to provide information on ecosystem change. It is only through such careful observation that we can evaluate the health of our natural resources and make science-based management decisions.

\section{Why is environmental monitoring important?}

Monitoring programs have been criticized as "costing too much while delivering too little."

However, environmental monitoring serves a vital scientific role by revealing long-term trends that can lead to new knowledge and understanding. For example, Charles David Keeling's long-term measurements of atmospheric carbon dioxide at Mauna Loa, HI provided the first unmistakable evidence that carbon dioxide emissions from human activities were warming the Earth. As a result of Keeling's and other scientists'careful and consistent monitoring, global climate change is now widely accepted as scientific fact.

Monitoring is also essential for evaluating environmental planning and policy. Without monitoring, projects cannot prove their success or identify areas for improvement. For example, the effectiveness of nearly $\$ 15$ billion of river restoration projects - initiated in the U.S. since 1990 - is not known due to the absence of monitoring. Due to its unique contributions to science and practice, monitoring is an integral aspect of ecological research, management, and policy.

\section{What is the scientific basis for monitoring?}

Monitoring, research, and modeling are three legs of a stool that provides scientific support for ecosystem restoration and management. Monitoring tells us what is happening, research tells why something is happening, and modeling helps to tell us what can happen. Scientific monitoring programs go beyond merely counting species; they are integrated into research objectives, based on compelling questions, and guided by ecosystem theory. Monitoring programs can be designed to test hypotheses or to validate quantitative models used for planning and policy. Long-term observations also reveal trends and patterns that can help interpret experimental results or yield new research hypotheses. Viewed in this manner, monitoring is a valid and important endeavor within the realm of ecosystem science that deserves stronger commitments from government agencies and other funding institutions.

\section{How does monitoring relate to adaptive management?}

Ecosystems are complicated. We usually do not know how they will respond to management or restoration activities. Adaptive management is an organized system of learning designed to reduce uncertainty inherent in ecosystem management. The active component of this learning process consists of experimentation, and the passive component is monitoring. Given constraints of time, money, and space, monitoring has become the primary path for learning in adaptive management (Figure 1).

Scientists and managers should work together to develop scientific monitoring programs that track ecosystem responses to management. Monitoring also can be used to compare simulated model output with real world observations. Most importantly, monitoring is the "canary in the coal mine" that alerts us when management plans are not working or, on the other hand, are working well. The earlier we learn that positive or negative effects are occurring, the easier it is to justify the current plan or the less expensive it is to set the course right. That is the core of how adaptive management works. 


\section{Is monitoring cost effective?}

It can be hard to demonstrate that monitoring is worth the cost. Monitoring may not be as satisfying as "turning dirt" during project implementation, and its benefits may not be immediately apparent. However, monitoring is the foundation for sciencebased adaptive management. It helps determine if a policy is having its intended results. By detecting problems early, monitoring can prevent catastrophes and "train wrecks" that too frequently characterize our interaction with nature.

How much should monitoring cost? The cost of monitoring should be commensurate with the size, importance, and risks of a project. In general the cost of monitoring is a small fraction of the overall cost of a project. It is also usually a small price to pay in light of the benefits that come from successful management and restoration of ecological systems.

A number of large-scale ecosystem restoration projects (Greater Everglades, Chesapeake Bay, coastal Louisiana, Great Lakes, Salton Sea) are currently underway in the United States. Had ecosystem monitoring programs been implemented long ago, the spatial extents, monetary costs, and ecological risks of these projects could have been greatly decreased. We may minimize or reduce the mistakes of the past. It is imperative to monitor these restoration efforts now to ensure their success and increase their future cost effectiveness.

\section{What does monitoring mean for the Everglades Restoration Plan?}

The Water Resources Development Act of 2000 (WRDA 2000) authorized the Comprehensive Everglades Restoration Plan (CERP) (www.evergladesplan.org) as the focal point of the South Florida Ecosystem Restoration Initiative. WRDA 2000 requires that CERP take an adaptive management approach to Everglades restoration. The adaptive management program for CERP includes a monitoring and assessment plan (MAP) to help understand ecosystem responses to restoration projects.

about weather, rainfall and
changes in vegetation or
land-use forms a
foundation for today's
and tomorrow's planning,
operations, research and
restoration initiatives."
- South Florida Water
Management District

MAP has three main objectives: (1) improve the understanding of the cause and effect relationship among key ecological and hydrological linkages; (2) test, evaluate and improve working hypotheses; and (3) provide information necessary for implementing adaptive management.

These goals are vital for continued management and restoration of the Everglades. Without careful and consistent monitoring of management policies and practices, there is little opportunity to evaluate and adjust projects, and thus a slimmer chance of success. Everglades ecosystems will not be restored using a business as usual approach. Adaptive management and environmental monitoring bring a fresh approach and new hope to restoring one of the world's most valuable and unique ecosystems - the greater Everglades.

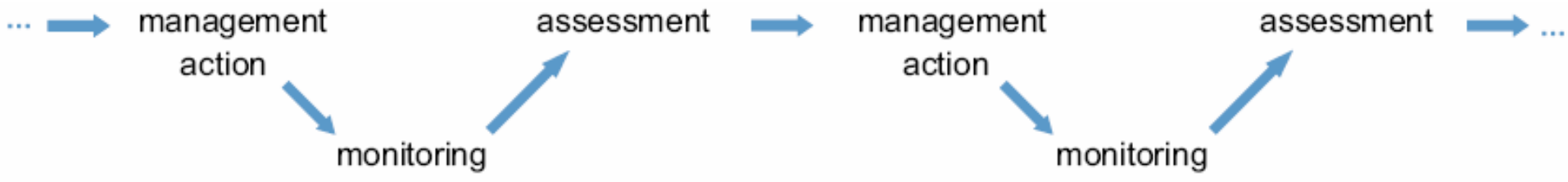

time

Figure 1. Iterative cycle of adaptive management (Williams et al. 2007).

\section{Sources}

Barrows, C.W., and M.F. Allen. 2007. Biological monitoring and bridging the gap between land management and science. Natural Areas Journal 27(2):194-197.

Lovett, G.M., D.A. Burns, C.T. Driscoll, J.C. Jenkins, M.J. Mitchell, L. Rustad, J.B. Shanley, G.E. Likens, and R. Haeuber. 2007. Who needs environmental monitoring? Frontiers in Ecology and the Environment 5(5):253-260.

Williams, B.K., R.C. Szaro, and C.D. Shapiro. 2007. Adaptive Management: The U.S. Department of the Interior Technical Guide. Adaptive Management Working Group, U.S. Department of the Interior, Washington, DC.

\section{Photo Credits (top to bottom)}

Michael Cherkiss, 2007; Shona Wilson, 2007; Michele Casler, 2003; Michael Rochford, 2006; Michele Casler, 2003; Shona Wilson, 2007 University of Florida, Ft. Lauderdale Research \& Education Center

UF | FLORIVRIDITA

IFAS Extension
For more information contact:

Frank J. Mazzotti

University of Florida, Fort Lauderdale Research \& Education Center

3205 College Ave., Davie, FL 33314

Email: fjma@ufl.edu

http://crocdoc.ifas.ufl.edu/ 


\section{Footnotes}

1. This document is WEC 241, one of a series of the Department of Wildlife Ecology and Conservation, Florida Coopertive Extension Service, Institute of Food and Agricultural Sciences, University of Florida. First published: November 2007. Please visit the EDIS Web site at http://edis.ifas.ufl.ed.

2. Frank J. Mazzotti is Associate Professor; Nicola Hughes is a Wildlife Intern; and Rebecca G. Harvey is an Environmental Education Coordinator; Fort Lauderdale Research and Education Center, Institute of Food and Agricultural Sciences, University of Florida.

The Institute of Food and Agricultural Sciences (IFAS) is an Equal Opportunity Institution authorized to provide research, educational information and other services only to individuals and institutions that function with non-discrimination with respect to race, creed, color, religion, age, disability, sex, sexual orientation, marital status, national origin, political opinions or affiliations. For more information on obtaining other extension publications, contact your county Cooperative Extension service.

U.S. Department of Agriculture, Cooperative Extension Service, University of Florida, IFAS, Florida A. \& M. University Cooperative Extension Program, and Boards of County Commissioners Cooperating. Larry Arrington, Dean.

\section{Copyright Information}

This document is copyrighted by the University of Florida, Institute of Food and Agricultural Sciences (UF/IFAS) for the people of the State of Florida. UF/IFAS retains all rights under all conventions, but permits free reproduction by all agents and offices of the Cooperative Extension Service and the people of the State of Florida. Permission is granted to others to use these materials in part or in full for educational purposes, provided that full credit is given to the UF/IFAS, citing the publication, its source, and date of publication. 